\title{
A Morte do Menino Italo e a Letalidade de Ações Policiais na Cidade de São Paulo: Um Estudo de Caso
}

\author{
Valtecino Eufrásio Leal \\ Professor universitário. Servidor público federal. Doutor \\ em Direito pela Faculdade Autônoma de Direito de São \\ Paulo-Fadisp. valtecino@gmail.com
}

\section{Geruza Silva de Oliveira Vieira}

Professora universitária. Doutora em Sociologia pela UFG. gsocienciasociais@gmail.com

\section{Rildo Mourão Ferreira}

Professor universitário. Doutor em Ciências Sociais pela PUCSP. rildomourao@uol.com.br

\section{Resumo}

Objetiva este artigo empreender uma análise da letalidade da ação policial que em acompanhamento tático, alvejou e vitimou com um tiro o menino Italo de Jesus Ferreira Siqueira, 10 anos, em flagrante de ato infracional, consistente na subtração de um veículo. Na pesquisa de cunho compilativo de dados bibliográficos e eletrônicos, pretende-se deduzir e demonstrar que 0 uso da força policial não é uma opção matemática ou de aplicação pura e simples da Justiça, especialmente na capital paulista, em que as mortes por ações policiais entrecruzam-se com dilemas da legítima defesa dos próprios agentes de segurança pública e da sociedade cada vez mais sitiada pela criminalidade que avassala os grandes centros urbanos. Conclui-se que os desafios nessa área remontam à necessidade de densificação dos investimentos em efetivos e preparação policial, mas não se pode excluir 
do desdobramento causal a realidade humana do decidir em fração de segundos, nas ocasiões de confronto em que o estresse do agir repentino pode significar a perda da vida do policial ou de pessoas à volta da crise enfrentada.

Palavras-chave: Criminalidade. Conduta policial. Segurança. Proteção da sociedade.

\title{
The death of the Italo boy and the lethality of police actions in the city of São Paulo: a case study
}

\begin{abstract}
Objective this article, undertake an analysis of the lethality of police action in tactical accompaniment, shot and killed with a shot to the boy Jesus Italo Ferreira Siqueira, 10, in the act of an offense consisting in the abduction of a vehicle. In recompiling nature of research of bibliographic and electronic data is intended to deduce and demonstrate that the use of police force is not a mathematical option or pure and simple application of justice, especially in São Paulo where deaths from police action intersect dilemmas of legitimate defense of their own public security agents and society increasingly besieged by crime that overwhelms the major urban centers. It is concluded that the challenges in this area date back to the need for densification of investments in effective and police training, but one can not exclude the causal unfolding human reality of deciding in a split second, the confrontation of times when the stress of acting sudden can mean the loss of police life and people around the crisis facing.
\end{abstract}

Keywords: Crime. Police conduct. Safety. Protection of society.

Recebido em: 17/12/2016

Aceito em: 12/4/2017

\section{Sumário}

1 Introdução. 2 A morte de uma criança infratora num quadro de violência urbana. 30 medo e a conduta das pessoas vitimadas. 4 A violência da situação hipotética e algumas iniciativas do Direito norte-americano. 5 Reflexões finais. 6 Referências. 


\section{INTRODUÇÃO}

Neste artigo científico, a partir de um caso concreto, consistente na morte de uma criança, alvejada a tiro pela Polícia Militar do Estado de São Paulo, em situação de perseguição após subtração de um veículo, pretende-se examinar as responsabilidades individuais, coletivas e do Estado, bem como as contingências e facticidades do medo e da alteridade, para além das intenções objetivistas pensadas no substancialismo das reflexões acadêmicas ou humanistas de laboratório.

A vertente de investigação focaliza-se na argumentação à volta da banalização do mal, somada a alguma interconexão com o legado autoritário ${ }^{1}$ e nas adjacências do temor generalizado, sobretudo em grandes centros urbanos brasileiros, alguns destes solapados por cenários típicos de domínio por grupos criminosos que a cada dia avançam gradualmente contra a sociedade, passando a impressão de que o Plano Nacional de Segurança Pública (2003) - que apontou sobre o fato de a maioria dos policiais brasileiros arriscar a vida para cumprir seu dever, em troca da ingratidão do Estado, da desvalorização profissional e de salários aviltantes - resultou num fracasso. Da mesma forma, as ações sociais de prevenção estimuladas a partir da teoria broken windows não têm resultado em contenção ou mitigação das condutas delituosas (RIBEIRO; PATRÍCIO, 2008).

Em São Paulo, há preleção de redução dos homicídios dolosos e, em via oposta, aumento dos homicídios praticados por policiais em ação (SINHORETTO; SCHLITTLER; SILVESTRE, 2016), mas a regra é de que os vilões sociais, em várias metrópoles brasileiras, atuam em progressões alarmantes e fixam bases territoriais de mando, nas quais a polícia

${ }^{1}$ Para Cesarini e Hite (2004, p. 4), trata-se de “[...] regras, procedimentos, normas, padrões, práticas, disposições, relações e memórias originadas em experiências autoritárias passadas bem definidas que, como resultado de configurações históricas específicas e/ou disputas políticas, sobrevivem à transição democrática [...]”. 
e cidadãos livres costumam receber boas-vindas a tiros. ${ }^{2}$ Enquanto isso acontece, muitos bons brasileiros, conquanto procurem levar vida honesta, vivem metodicamente descompromissados com o semelhante, como se esse olhar fosse de exclusiva responsabilidade do Estado, das instituições e de seus agentes.

A uma observação mais arguta, deseja-se um despertar para o fato de o homem não enxergar e não incluir o outro em suas ações existenciais e no modo individualista de viver em sociedade e talvez por isso esteja fadado a reencontrá-lo em situações de confronto, como se fosse possível, nessa ruptura, simbolizar uma luta entre seres esquecidos em cantos de exclusão e outros, realizados socialmente. Pretende-se também ponderar que o mal lido em Bauman e Donskis (2013), inerente ao indivíduo, à coletividade e ao Estado, é fator preponderante para desfechos sociais graves, especialmente se banalizado ou praticado de maneira egoística e invisível pelo homem deste terceiro milênio.

\section{A MORTE DE UMA CRIANÇA INFRATORA NUM QUADRO DE VIOLÊNCIA URBANA}

O humano massificado dessa primeira metade do século 21 depara-se com vaticínios funestos e dilemas morais de difícil equalização. Por um lado, há enfrentamentos intelectivos de ordem econômica e a preocupação com realizações neocapitalistas. Em outro aspecto, nos opomos uns aos outros e muitos de nós vivemos sem compreender as razões sociais das brutalidades a partir de atuações criminosas, de conflitos religiosos, de terrorismo e de violência urbana. Na velocidade do mundo digital, homens

${ }^{2}$ Conforme Cardia (2013), há indicadores de que em São Paulo, num período de 9 meses, 176 policiais militares foram feridos em ocorrências criminais e 13 foram mortos. De outro lado, 379 pessoas foram mortas pela Polícia Militar no mesmo período. Da mesma forma, em centros urbanos, o tráfico de entorpecentes cresceu de modo substancial e generalizado nas últimas décadas (de 21,7 para 85,4 por 100 mil habitantes). 
e mulheres não conseguem parar seu estilo de vida e olhar para o semelhante como humano e por isso, desconhecem o milagre de reconhecer a personalidade e a dignidade do ser e de que o eu perante o outro deve ser infinitamente responsável (LEVINAS, 2009). Digressões como essas, entretanto, em relação ao valor que devo enxergar em meu semelhante, estão a exigir, cada vez mais, pensares ontológicos de identidade.

As pessoas vivem de coalizões entre o bem e o mal ou entre o bom e o ruim. O que é mal para alguém, todavia, em algumas perspectivas, passa a ser o meio para outro visualizar o seu bem, num simbolismo paradoxal, demarcado entre o que se faz no dia a dia para se alcançar objetivos delimitados e o que se deveria fazer nos espaços sociais de reconhecimento do eu como ser social. Bauman e Donskis (2013, p. 15) advertem sobre a existência de uma "Geografia simbólica do mal” e se referem ao fato de vivermos num mundo de estereótipos e convicções, em que o mal não é inerente apenas a nós individualmente, mas também às sociedades, às comunidades políticas e aos países.

Retrato equivalente foi visualizado em meados do século 20 por Arendt (1999, p. 299), ao contextualizar sobre a banalização do mal e ponderar que Eichmann, durante a Segunda Guerra Mundial, era um “hostis generis humani, que comete seus crimes em circunstâncias que tornam praticamente impossível para ele saber ou sentir que está agindo de modo errado”. Em outras palavras, o general apenas demonstrou que nos campos de concentração executava ordens normalmente, bem ao estilo de um soldado da morte, e socialmente levava vida normal, como se a sua função no Holocausto significasse apenas uma rotina de trabalho como qualquer outra. Em sua convicção de patriota, era um ser sem pensares além do seu campo de atuação profissional e em sociedade representava o cidadão que usufruía de singular prestígio. 
Essa reflexão arendtiana que permeia pela ideia de pessoas destituídas de raízes perpassou por décadas e no Brasil, onde grassa o apogeu da violência urbana e suas imprevisibilidades, pode ser relida de várias maneiras, sobretudo neste século 21 , ao confronto de episódios como este ora analisado, envolvendo a morte de uma criança a tiro por policiais depois de abreviada perseguição.

Em síntese, o fato se deu após o menino Italo, ${ }^{3}$ com 10 anos de idade, ser alvejado na noite de 2 de junho de 2016, por disparo que o atingiu na cabeça, na região do olho esquerdo. Antes desse evento, o garoto já havia perpetrado furto em 31 de janeiro de 2016 e isso se repetiu em 22 de abril. Cometera também danos em veículos e invasão de domicílio em 28 de maio do mesmo ano. No dia de sua morte a criança achava-se na condução de um veículo importado subtraído instante antes, no Bairro do Morumbi, na capital de São Paulo.

Os dois policiais militares, ambos com 25 anos de idade, acionados para a ocorrência, realizavam acompanhamento policial tático, no intuito de reaver o veículo, subtraído do interior de um condomínio residencial, e agiam num caso que a par da configuração de violência urbana da cidade, aparentava risco imediato, como costuma acontecer em confrontos dessa natureza. Ao que consta, desconheciam que duas crianças se achavam no interior daquele carro, uma na condução, e isso, razoavelmente, era implausível, a considerar o próprio furto e a dirigibilidade em movimentada rua da Grande São Paulo.

\footnotetext{
${ }^{3} \mathrm{O}$ menino era filho de Cintia Francelino e Fernando Jesus Siqueira. A mãe possui em seus antecedentes ficha de flagrante por tentativa de roubo datada de novembro de $2006 \mathrm{e}$ outra de outubro de 2007, além de flagrante por roubo consumado de dezembro de 2007 e flagrante por furto de setembro de 2011. Em dezembro de 2014 foi procurada pelo Judiciário e capturada; e em dezembro de 2015, isso novamente se repetiu. O pai foi preso em flagrante por tráfico de entorpecentes em agosto de 2009 e noutra ocasião, em janeiro de 2013, foi flagrado por outro tráfico de entorpecentes e corrupção ativa. Notícia disponível em: <www.tjsp.jus.br>. Acesso em: 5 set. 2016.
} 
Existe versão por parte da polícia de que a criança deflagrou três disparos contra os policiais e, por esse motivo, ocorreu o revide. Ao mesmo tempo, há versões não oficiais de que não existiram esses disparos e que houvera simulação pelos agentes públicos, consistente na introdução ilícita de uma arma de fogo na cena do crime. Há titubeios nas informações trazidas por outra criança que se achava a bordo do veículo subtraído.

\section{O MEDO E A CONDUTA DAS PESSOAS VITIMADAS}

Os fatos e versões referidos, isoladamente, não são relevantes para o ponto de reflexão que se deseja formatar com esse texto científico, mas algumas indagações estarão sempre à volta de qualquer investigação séria e imparcial. Será que desejam alguns burocratas fazer crer que é normal uma criança de 10 anos subtrair um carro, portar arma de fogo e revidar com tiros? É normal ao agente público atirar em razão do medo natural de levar um tiro? É crível exigir que o policial, numa sociedade violenta, espere o ladrão atirar, para depois revidar? Numa metrópole, em que centenas de policiais, com alguma frequência, são vitimados em serviço por disparos de arma de fogo, quaisquer agentes que estivessem no lugar daqueles que perseguiam o veículo furtado, pilotando motos e extremamente vulneráveis no meio da avenida, em regra, atirariam primeiro.

Sem desejar formatar respostas prontas, na opinião dos autores deste trabalho, num lugar como São Paulo, policiais, na condição de cidadãos do meio urbano violento, também são as pretensas vítimas da guerra contra a selvageria que se trava no dia a dia e se veem constrangidos legalmente ao enfrentamento. ${ }^{4}$ Soa como superstição quase infantil desejar defender ou crer que esses humanos também submersos num mar de medo, devem aguardar o tiro inimigo para depois revidar. Esse refletir ou essa recomendação, em nossa cultura ainda

${ }^{4}$ Conforme dados levantados pela Unesco (https://nacoesunidas.org/unesco-mapa-da-violencia-revela-que-116-brasileiros-morrem-todos-os-dias-por-arma-de-fogo/. Acesso em: 9 set. 2016), no Brasil, 42.416 pessoas morreram em 2012 vitimadas por armas de fogo. Esse número, contudo, ainda é, de fato, mais alarmante, se houver análise de outras situações, como as mortes por armas brancas, por envenenamento, acidentes de trânsito, etc. 
instável, só podem existir na cabeça de algum burocrata ou jurisconsulto que jamais se ausentou do aconchego de seu recinto climatizado, ou decerto nunca experimentou o perigo de perto e que, na imersão de um mundo de fantasias, vive a conjeturar tessituras de realidades abstratas em quais direitos humanos fundamentalistas do papel, catalisariam forças inibidoras ou minimalistas dos riscos e dos medos interligados nessas brutalidades de ruas como aquelas são-paulinas.

Nesse quadro brasileiro mais consentâneo com a situação de uma batalha, todos, inclusive os policiais, estão oprimidos pela violência em expansão e esses agentes, em limbos de vida e de morte, alimentam-se de esforços para superar o estado de elevado estresse cotidiano decorrente de seus enfrentamentos e estão suscetíveis a praticar condutas que não deveriam, para evitar resultados danosos a si próprios ou a outros, mas que ao exame meticuloso e imparcial, pode não transparecer assim algo tão equivocado. Cônscio das suscetibilidades à volta do enfrentamento que fere centenas e mata muitos a cada ano, o servidor público sujeita-se a análises de justiça a todo instante. As tabelas a seguir bem retratam os riscos e os resultados dessas crises urbanas que ceifam vidas.

Tabela 1 - Mortes e lesões de policiais militares em serviço no Estado de São Paulo entre 2012 e 2015

$\begin{array}{lcccc} & 2012 & 2013 & 2014 & 2015 \\ \text { Total de mortes } & 14 & 18 & 14 & 13 \\ \text { Total de feridos } & 223 & 221 & 240 & 197\end{array}$

Fonte: Dados trimestrais da Secretaria de Segurança Pública do Estado de São Paulo. Disponível em: <www.ssp.sp.gov.br/novaestatistica/>. Acesso em: 20 set. 2016.

Tabela 2 - Mortes e lesões de civis no confronto com a Polícia Militar no Estado de São Paulo entre 2012 e 2015

$\begin{array}{lcccc} & 2012 & 2013 & 2014 & 2015 \\ \text { Total de mortes } & 546 & 334 & 693 & 580 \\ \text { Total de feridos } & 364 & 392 & 582 & 488\end{array}$

Fonte: Dados trimestrais da Secretaria de Segurança Pública do Estado de São Paulo. Disponível em: <www.ssp.sp.gov.br/novaestatistica/>. Acesso em: 20 set. 2016. 
O que se abstrai desses números são situações que merecem boas reflexões. Primeiro, vê-se que no ano de 2012 a Polícia Militar de São Paulo aumentou a repressão e os confrontos com agentes do crime, em razão do alto índice de policiais mortos fora do serviço (106 assassinatos), por supostas ações do grupo organizado, intitulado de Primeiro Comando da Capital (PCC). Em contrapartida, ocorreram 546 mortes de civis por policiais naquele ano.

No ano de 2013 a situação inverte-se. A polícia retrai na letalidade (total de 334 mortes), mas os grupos criminosos avançam e o número de policiais mortos em serviço, evolui de 14 para 18. Como se houvesse um jogo de puxa e solta, em 2014 a letalidade das ações policiais aumenta e os civis mortos passam de 334 para 693 e em contrapartida, o número de policiais mortos e feridos reduz-se e segue numa trajetória de queda em 2015 (13 mortes e 197 feridos).

Em razão desse panorama estatístico, há o risco das opções políticas e das polícias penderem para a solução da violência urbana, por meio da força, ao estilo hobbesiano no estado de natureza ou na lei do mais forte (1979), sem resultados para o médio prazo e isso acontece por algumas razões e hiatos peculiares. Não se pode deixar de vislumbrar, na linha de desdobramento da culpa, a ausência de políticas públicas adequadas nas muitas demandas comunitárias e, nesse sentido, é imperioso refletir sobre essa perigosa tensão em qual situam-se os poderes estatais e a sociedade brasileira. Indagação para uma boa reflexão desse ponto de partida pode ser deduzida do seguinte dilema proposto por Bauman e Donskis (2013, p. 16).

O que você diria sobre um ser humano que, numa noite, durante a Segunda Guerra Mundial, ouve bater à porta uma criança judia em busca de abrigo, na esperança de ser salva? O ser humano deve decidir na hora, sabendo muito bem que está arriscando a própria vida e a de sua família. Essa é uma situação que não se deseja para ninguém, nem para si mesmo (BAUMAN; DONSKIS, 2013, p. 16). 
Em proporções bem equivalentes, vale advertir, alguma coisa dessa natureza pode ter sucedido na impenetrável deliberação da encruzilhada moral daquela dupla de policiais que momentos antes receberam um comunicado sobre um furto perpetrado por infratores, que circulavam a bordo de um veículo próximo a eles. Naquele insólito momento, não existia tempo para se pensar no enigma humano do bom ou do justo. $\mathrm{O}$ veredito não poderia esperar análises de gabinete. $\mathrm{Na}$ linha de desdobramento de um serviço público ideologizado pelo caminhar ao encontro do infrator, a fim de evitar que ele cresça e avance contra todos, compreendeu-se como adequado o confronto e a ação que poderia levar, e levou, a resultados desastrosos.

Nesse cenário, por demais atormentador para a mente humana, não seria de admirar se na situação, por se tratar de São Paulo, mesmo que não houvesse arma na posse dos menores, os agentes sentissem o terror do risco imediato - repita-se, quem enfrenta um momento de decisão como esse sabe o quão infausto e estressante é a escolha - e decidissem alvejar o então indecifrável condutor do veículo importado. Naquela condição e na lei natural do tempo e do lugar, se a ordem de parada não foi atendida e se o carro já vinha em zigue-zague, não era minimamente plausível que aqueles agentes motociclistas aguardassem a colisão por uma fechada, esperassem o zumbido do aço ou mesmo que sentissem o tiro na pele, para somente depois atirar. Se assim alguém imaginar ou acreditar, certamente também defenderá que o policial brasileiro é preparado e remunerado para passiva e absurdamente ser ferido ou morrer para só depois se cogitar em reação ou defesa própria ou de outros.

Numa situação limite similar a essa, Sandel (2013, p. 33-36) narra um episódio ocorrido no Afeganistão, com soldados americanos que ingressavam no país para levantar informações do regime talibã. Ao desembarcarem próximo à fronteira do Paquistão, um suboficial e mais três seals depararam com dois camponeses afegãos e um adolescente pas- 
toreando cabras. Tinham os militares duas opções: matar os três civis ou deixá-los partir. Luttrell, o comandante, num senso pessoal cristão, deliberou pela soltura. Uma hora e meia depois, os quatro se viram cercados por cerca de cem combatentes talibãs armados de fuzis AK-47 e granadas de mão. No sangrento combate, os três seals foram mortos e Luttrell gravemente ferido. Um helicóptero americano de resgate com 16 soldados também fora abatido e o resultado da escolha trágica: 19 compatriotas do militar mortos. Luttrell somente se salvou porque rolou montanha abaixo e se arrastou por 11 quilômetros, chegando a um vilarejo, onde os moradores afegãos o mantiveram em proteção até o efetivo resgate.

Tal como esse fato da vida real, na rotina policial também são corriqueiras situações de análise de condutas guiadas por um senso de justiça. O caso de São Paulo foi emblemático e de possibilidades várias. Os confrontos entre criminosos e policiais repetem-se muitas vezes nos grandes centros, em regiões interioranas do país e no mundo. Ninguém pode apenas criminalizar ou simplesmente escolher uma posição. Afirmar que apesar de tudo era só uma criança indefesa ou que se deve condenar os policiais pela letalidade da ação, pode não ser uma escolha justa, muito embora se acredite que algum burocrata, com melhores pontos de partida em relação aos dois policiais, especialmente porque terá tempo e sossego para refletir, emitirá alguma decisão também desastrosa, simplesmente por pressão midiática, proteção institucional ou por alternativa tida como justa.

Nessa linha, é possível e quase certo que os policiais eram e são homens de bem e estavam apenas cumprindo um papel que a sociedade de governos e de pessoas descompromissados com a alteridade lhes delegou. Também é inverossímil que o pequeno Italo apenas estivesse perdido e sem nenhum auxílio nesse mundo de gente que sequer ligava se ele dormia ou vivia nas ruas. Só não é correto que após o desastre esses mesmos gestores e a comunidade corresponsável lavem suas mãos, 
apenas censurem a ação policial ou lamentem a morte da criança. Se assim acontecer, o argumento de Arendt de banalização do mal, ou mesmo o argumento niilista prevalecerá mesmo após várias décadas e agora, governos e cidadãos apenas cuidarão de contabilizar mais uma morte e de censurar ou substituir seus agentes públicos.

Em Goiás, no mês de julho de $2016,{ }^{5}$ um policial militar experiente, com 47 anos de idade, que não dispunha de armamento não letal, tentava conter e prender uma pessoa bêbada que se recusava a obedecer à legislação. No imbróglio, uma terceira pessoa, ao visualizar o infrator atracado ao sargento, sacou a arma do coldre deste último e assassinou o agente público. Houve uma escolha para solução da situação apenas com o contato físico. O segundo policial que atuava no episódio também foi alvejado gravemente, embora tenha abatido o perspicaz agressor homicida.

Por evidente, argumentos de justiça devem ocupar um lugar de destaque na solução dessa modalidade de crise de humanismo. O que não se deve é "coisificar" o ser humano e apenas aceitar que isso aconteça naturalmente. Não se deve apenas burocratizar os acontecimentos, a partir de uma solução mecanizada, ao estilo das decisões de Eichmann. Isso equivaleria a dizer que o homem decente não sabe ou não quer domar o monstro que abriga dentro de si, numa reinterpretação do pensar de Bauman e Donskis (2013, p. 26).

Justo seria se não desejássemos apenas censurar, mas olhar para os policiais militares mal remunerados, ${ }^{6}$ atuantes num cenário de violência urbana de poucas perspectivas e que ainda assim não se descuidam de

${ }^{5}$ Notícia disponível, inclusive com vídeo do fato, no site $<$ http://www.opopular.com.br/editorias/vida-urbana/sargento-da-pm-\%C3\%A9-assassinado-ao-atender-ocorr\%C3\%Aancia-de-som-alto-1.1114859>. Acesso em: 21 set. 2016.

6 No último concurso da Polícia Militar de São Paulo, a remuneração divulgada era de R\$ 2.242,00. Ver link: http://www.vunesp.com.br/viewer/visualiza.html?file=/pmes1201/ edital_pmes1201_2.pdf. Acesso em 3 set. 2016; em Goiás, o subsídio é de RṢ 1.841,00. Ver: www.nucleodeselecao.ueg.br/PDFs/concursos/143/ Aviso_de_Edital_Concurso_PM- 
seguir ao lado de um veículo objeto de crime, sem saber ou conhecer o antes e o depois daquela perseguição, até porque, no estresse dos acontecimentos policiais, não há tempo para esclarecimentos ou para longas explicações antecedentes ao confronto. E não basta dizer que eles são pagos para enfrentar o risco e que sabem ou deveriam saber atuar de maneira menos lesiva ao outro naquele quadro periclitante.

Crer somente no legado autoritário ou no padrão policial sem freios que privilegie memórias de experiências autoritárias ou históricas passadas, para debelar a criminalidade ou a violência, é retroalimentar o discurso do ódio ou do tudo ou nada, ou ainda, o separatismo delimitado entre classes sociais que a um exame mais meticuloso restitui o intérprete ao niilismo. Se a democracia da realização pessoal e a própria cultura brasileira de valoração das riquezas, aliadas ao sonho de alcançá-las de maneira célere e com o mínimo esforço, parecem a melhor escolha da sociedade; e se o fortalecimento de valores fundamentais como a educação, a família, a religião e outros, ainda enfrentam tempos de transição e não existem ativismos sociais relevantes a indicar vias de consenso para facilitar a governança e diminuir a violenta exclusão social; se os problemas sociais e políticos passam a depender diretamente de instituições como a polícia, o Ministério Público e o Judiciário; concebe-se que a justiça passa a significar insights pessoais para cada um dos envolvidos em situações sociais limites. De um lado, alguém entende que não é justo viver na exclusão e decide que é preferível enfrentar a morte na tentativa de uma chance para a obtenção de alguma realização e de outro, alguns julgam que é justo enfrentar e até matar, em legítima defesa, o ser social que tenta quebrar a hegemonia dos resultados neocapitalistas adotados pelo país.

-Praca-2012.zip. Há notícia, porém, de que no próximo concurso o subsídio será na ordem de R\$ 1.500,00. Disponível em: <http://diariodegoias.com.br/cidades/23285-governo-fara-concurso-na-pm-e-policia-civil-com-faixa-de-salarios-mais-baixos>. Acesso em: 4 set. 2016. 
Infelizmente os policiais brasileiros, em sua maioria, vivem no limbo e não são remunerados ou treinados adequadamente para esse tipo de enfrentamento e tomada de decisão. Muitos perecem em combate e há na grande São Paulo um número significativo de agentes do crime que por motivos fúteis sentem-se "motivados" a executar um agente da lei. Ao mesmo tempo, dois policiais jovens, em regra, são desejosos por boas realizações profissionais e não foi, não é e nunca será a rotina das polícias atirar numa criança a bordo de um veículo, se conhecida essa condição, e no mais, se ensina e se aprende nas Academias de Polícia brasileiras que se um agente praticar esse ato, se errar numa ação e atingir um inocente, levará para sempre o pesadelo ou um fantasma e é por isso que não há dúvidas de que os policiais atuantes no caso Italo também figuram como vítimas de um sistema de segurança pública falho e deficitário.

Ao mesmo tempo, explicar sobre Italo e sua condição de vítima é também ressalvar que o Estado e a sociedade civil brasileira são vilões e não se ocupam em resolver problemas sociais graves, como o da criança que vivia na pele a violência e os arroubos da indignidade e do abandono, dormindo nas ruas e convivendo com males nefastos para qualquer pessoa, cujos pais eram criminosos do roubo e do tráfico de drogas. $\mathrm{O}$ menino de infância roubada, sozinho no mundo, sem rumos e sem orientação, num tempo de ilusões e de medo, embora por caminhos ilícitos, apenas buscava sobrevivência a partir do exemplo dos pais, enquanto o Estado e a sociedade que se proclamam orientados pela cidadania e dignidade humana deixaram de conferir a ele a chance de um abrigo digno, bem como o alcance de outros direitos fundamentais.

7 Isso aconteceu com maior ênfase em 2012, quando 229 policiais morreram em São Paulo, 44 só na grande capital, em situação típica de extermínio por grupos criminosos (DIAS et al., 2015). 
Fatos como esses devem fundar-se em argumentos de justiça e no simbolismo dos direitos humanos que se constroem e se reconstroem na história de cada povo (ARENDT, 1979). Assim, se parece desumano imaginar uma criança morta a tiros pela polícia, ao mesmo tempo isso também se antagoniza com o difícil dilema humano de agentes em patrulha sobre motos, vulneráveis e suscetíveis a riscos de toda sorte, em meio à violência da Grande São Paulo, que avança inclusive sobre as polícias, ${ }^{8}$ deixando um rastro de medo generalizado. É injusto adotar condutas apressadas, mas também não é justo que a sociedade fique à mercê das ações de agentes criminosos como o pai e a mãe da criança, que legaram a esta, como escola, apenas o abandono e a prática de atos que a levaram ao encontro de um cenário de guerra urbana em que o matar ou o morrer poderiam decorrer da fração de uma escolha tomada em altíssimo nível de estresse.

\section{A VIOLÊNCIA DA SITUAÇÃO HIPOTÉTICA E ALGUMAS INICIATIVAS DO DIREITO NORTE-AMERICANO}

A violência e a letalidade de ações como a do caso Italo também estão na linha de preocupação das políticas e das polícias brasileiras, afinal, a segurança pública efetiva demanda que ações urgentes aconteçam, tanto em favor das comunidades e seus integrantes, incluindo-se os próprios agentes da lei e os infratores. Com o passar dos anos muitas ações foram adotadas no país, como as rondas táticas em locais de recorrência de ações criminosas; as Unidades de Polícias Pacificadoras no Rio de Janeiro - RJ

8 Conforme notícia publicada no endereço <sao-paulo.estadao.com.br/noticia $>$, em 16 de abril de 2016 já eram contabilizados 27 homicídios de PMs no Estado de São Paulo. Em 2015 foram 136 assassinatos. 
a partir de 2008; as abordagens educativas; a lei seca no trânsito; o policiamento ostensivo sobre motos em São Paulo e outras, mas ainda será necessária uma longa caminhada.

Nos Estados Unidos da América, a situação de enfrentamento da criminalidade vem de algumas décadas e há diversas iniciativas. Uma delas é a focused policing ou policiamento com foco, a significar, conforme Waller e Sansfaçon (2000, p. 15), o policiamento estratégico, orientado para problemas delimitados que levem em conta diagnósticos precisos, planejamentos e avaliações sistemáticas, além de metas ligadas a valores adotados pela própria comunidade. Essa atuação teria como objeto as expectativas sociais sobre as melhores ações de proteção no âmbito da segurança pública.

No referido estudo foram apontados alguns fatores de risco (2000, p. 5) que contribuiriam para a prática de condutas criminosas nos EUA. Algumas delas dizem respeito à relativa pobreza, a lares desestruturados, inconsistência e insuficiência de proteção familiar, limitações nas habilidades para valoração da convivência social, exclusão das escolas, famílias violentas, falta de oportunidades ou de empregos e cultura social da violência.

No plano de segurança pública brasileiro de 2003 também se deixa evidente que na Inglaterra, nos Estados Unidos e na Holanda diversas iniciativas mostraram-se eficientes para a redução da delinquência, incluindo-se a escola para a parcela pobre do país, o apoio e assistência a famílias excluídas, a oferta de incentivos financeiros para os estudos de crianças e adolescentes e o aumento do número de profissionais que atuam com vigilância pública.

Não se pode negar que muitos anos após aqueles estudos, os dados ainda são perfeitamente aplicáveis ao Brasil e quase todos os fatores relacionados acham-se presentes no caso de Italo, ora em exame. Fica aqui a impressão de que a história se repete em vários cantos do país e do mundo, com pequenas variações de cultura. No fundo, parece ser a exclu- 
são social a principal razão da violência e da criminalidade. Por essa linha, é necessário pensar em políticas de mitigação da pobreza extrema, mas também é inevitável a fixação de programas governamentais e sociais de estímulo à proteção familiar, à permanência das crianças e jovens na escola e à ampliação de empregos no país.

\section{REFLEXÕES FINAIS}

Algumas questões facilitam a compreensão tanto da ação policial quanto a conduta da criança, que se inserem num modelo estereotipado de convicções, no qual ninguém pode apenas imputar culpa ou classificar-se sozinho como culpado, mas todos podem considerar-se como corresponsáveis, numa reassimilação da teoria da coculpabilidade nos termos defendidos expressamente por Zaffaroni (1982, p. 168), para quem existem pessoas com autodeterminação de menor alcance, especialmente por condicionamento de causas sociais e nessa hipótese a sociedade também tem parcela de responsabilidade na conduta antijurídica. Noutra linha, Mello (2005, p. 927) argumenta que se existir serviço defeituoso, isso bastará para configurar a responsabilidade do Estado.

Assim, a par da busca de autodeterminação e em alguns casos de autopreservação, próximos da lex naturalis hobbesiana, a culpa pela violência social e a ofensa à dignidade humana, são atribuíveis a um somatório de corresponsáveis, ou seja, aos pais, aos gestores políticos, aos policiais e à sociedade. Conforme levantado, no interior de um condomínio residencial, facilmente acessível por duas crianças, via muros, alguém deixou um carro destrancado e com as chaves na ignição. Isso facilitou o acesso das crianças ao veículo e o serviço de vigilância do condomínio, negligentemente, permitiu a saída. Enfim, muitos foram aqueles que protagonizaram o episódio e que de modo indireto deixaram de outorgar ao menino a chance de um lar, de uma escola, de um abrigo ou de viver. 
Nessa convergência de volatilidade, o país foi e continua omisso em seu papel de garantidor das prestações e direitos sociais e desse modo, é verossímil, como defendem Bauman e Donskis (2013), que esses fatos aconteçam e ainda irão ocorrer no Brasil, em razão do mal inerente a nós individualmente e também à sociedade, às autoridades políticas e ao país.

Não é plausível, ademais, que se deixe de refletir sobre o gradual aumento do efetivo de policiais em serviço, relativamente ao quantitativo de habitantes. ${ }^{9}$ Isso, aliado ao treinamento contínuo e à prevenção social situacional que o quadro atual exige, pode minimizar a onda de práticas criminosas, como furtos, roubos e mortes violentas. A sociedade também pode colaborar em maior grau, com comportamentos favoráveis à autopreservação e, nesse ponto, talvez possam servir como lições algumas das advertências preconizadas pela teoria novaiorquina broken windows. Embora a aparente divergência, as janelas quebradas indicam que desordem gera desordem e quanto a isso, o caminho mais seguro nesse país ainda fica para a prevenção, ou seja, o trancamento de portas e janelas, não portar quantias em dinheiro em bolsas ou caixas de comércio, evitar os passeios em determinados locais e horários, dirigir veículos de maneira defensiva, entre inúmeras outras ações de autoproteção. Ou, noutras palavras, zelar para que sejam minimizadas as quantidades de janelas quebradas, a fim de se evitar a pressuposição de ausência do Estado e de leniência das pessoas com o zelo e a autodeterminação de proteção coletiva.

Se estamos no rumo certo? Não é fácil saber a resposta. No plano político, o que se enxerga é a ausência evidente de segurança para os cidadãos, num plano de acontecimentos em que o Estado não consegue

9 No Brasil, em 2015, segundo dados do governo federal, havia um policial militar para cada 473 habitantes (disponível em: <http://www.brasil.gov.br/defesa-e-seguranca/2015/08/ brasil-tem-um-pm-para-cada-473-habitantes-aponta-ibge >. Acesso em: 5 set. 2016). É importante ressalvar que se for considerada a situação de escalas de revezamento (o efetivo referido não chegaria a um policial por 1.200 habitantes), bem como a ausência de concurso na maioria dos Estados, entre 2015 e 2016, atualmente, esse quantitativo está extremamente precarizado. 
garantir adequado efetivo de policiais em serviço diuturno e aqueles que estão no front acham-se em desvantagens de toda ordem em relação ao crime organizado ou sem o necessário treinamento ou respaldo jurídico para o confronto com os inimigos públicos. No que muitos consideram a "guerra contra o crime”, a sociedade figura como colaboradora, ou seja, não possui vigilância permanente e pouco atua para preservar a liberdade e a cidadania. $\mathrm{E}$ as práticas rotineiras tornam-se favoráveis à ação dos grupos e agentes infratores e por enquanto, a tendência é o estado de conflito hobbesiano, em que a lei do mais forte tende a prevalecer.

Acenos como a criação de programas sociais de assistência alimentar, sistemas de cotas e outros mecanismos de proteção de grupos em limbos de pobreza são ideais, mas também é necessário evitar que a exclusão social que fomenta a percepção de injustiça social progrida, ou minimizar os impactos e a evolução da violência e para isso é essencial que o Estado brasileiro se reestruture e alcance um estágio de prestação favorável à proteção ampla das pessoas que vivem à margem da pobreza extrema. Também é urgente manter estruturas de segurança pública, equidistantes da atuação autoritária e do modelo punitivo de mero encarceramento. O que se espera é que nossas polícias mereçam melhor preparação, sejam destituídas do medo de agir e capazes de combater com segurança jurídica as ações de grupos ou indivíduos criminosos. E que outros policiais ou outros Italos não se tornem as novas vítimas dos dias e noites de violência deste país que caminha na contramão de um sistema de segurança pública minimamente desejável.

\section{REFERÊNCIAS}

ARENDT, Hannah. Entre o passado e o futuro. Trad. Mauro Barbosa de Almeida. São Paulo: Perspectiva, 1979. 
ARENDT, Hannah. Eichmann em Jerusalém, um relato sobre a banalidade do mal. Trad. José Rubens Siqueira. São Paulo: Companhia das Letras, 1999.

BAUMAN, Zygmunt; DONSKIS, Leonidas. Cegueira moral: a perda da sensibilidade na modernidade líquida. Rio de Janeiro: Zahar, 2013.

BRASIL tem um PM para cada 473 habitantes, aponta IBGE. Disponível em: <http://www.brasil.gov.br/defesa-e-seguranca/2015/08/brasil-tem-um-pm-para-cada-473-habitantes-aponta-ibge>. Acesso em: 5 set. 2016.

CARDIA, Nancy. Atual situação de violência - crise na segurança pública em São Paulo? Cienc. Cult., São Paulo, v. 65, n. 1, jan. 2013.

CESARINI, Paola; HITE, Katherine. Introducing the concept of authoritarian Legacies. In: CESARINI, Paola; HITE, Katherine (Coord.). Authoritarian Legacies and democracy in latin America and Southern Cone. Notre Dame: Notre Dame University Press, 2004.

DIAS, Camila et al. A prática de execuções na região metropolitana de São Paulo na crise de 2012: um estudo de caso. Revista Brasileira de Segurança Pública, São Paulo, v. 9, n. 2, p. 160-179, ago./set. 2015.

HOBBES, Thomas. Leviatã ou matéria, forma e poder de um estado eclesiástico e civil. Trad. João Paulo Monteiro e Maria Beatriz Nizza da Silva. 2. ed. São Paulo: Abril Cultural, 1979.

LEVINAS, Emmanuel. O humanismo do outro homem. 3. ed. Petrópolis: Vozes, 2009 .

MACHADO, Leandro. Ninguém trará meu filho de volta, diz mãe de menino morto pela PM em SP. Folha de São Paulo on-line. Disponível em: <http:// www1.folha.uol.com.br/cotidiano/2016/06/ 1777901-era-uma-crianca-naovai-adiantar-nada-diz-mae-de-menino-morto-pela-pm.shtml>. Acesso em: 30 jul.2016.

MAPA da violência 2015. Mortes matadas por armas de fogo. Disponível em: <http://www.mapadaviolencia.org.br/pdf2015/mapaViolencia2015.pdf>. Acesso em: 31 ago. 2016. 
MELLO, Celso Antônio Bandeira de. Curso de Direito Administrativo. 18. ed. São Paulo: Malheiros, 2005.

PLANO NACIONAL DE SEGURANÇA PÚBLICA, 2003. Disponível em: $<$ http://www.justica.gov.br/sua-seguranca/seguranca-publica/senasp-1/pnsp. pdf>. Acesso em: 2 set. 2016.

RIBEIRO, Ludmila; PATRÍCIO, Luciane. Indicadores para o monitoramento das políticas municipais de segurança pública: uma reflexão a partir de um estudo de caso. Revista Brasileira de Segurança Pública, v. 2. n. 3, p. 6-29, 2008. SANDEL, Michael. Justiça: o que é fazer a coisa certa. Trad. Heloisa Matias e Maria Alice Máximo. São Paulo: Civilização Brasileira, 2013.

SINHORETTO, Jacqueline; SCHLITTLER, Maria Carolina; SILVESTRE, Giane. Juventude e violência policial no município de São Paulo. Rev. Bras. Segur. Pública, São Paulo, v. 10, n. 1, 10-35, fev./mar. 2016.

UNESCO: mapa da violência revela que 116 brasileiros morrem todos os dias por arma de fogo. Disponível em: $<$ https://nacoesunidas.org/unesco-mapa-da-violencia-revela-que-116-brasileiros-morrem-todos-os-dias-por-arma-de-fogo/>. Acesso em: $1^{\circ}$ set. 2016.

WALLER, Irvin; SANSFAÇON, Daniel. Investing Wesely in Crime Prevention International Experiences. U. S. Departament of Justice: Washington D. C., 2000. Disponível em: <https://www.ncjrs.gov/pdffiles1/bja/182412.pdf>. Acesso em: 6 set.2016.

ZAFFARONI, Eugênio Raúl. Política criminal latinoamericana. Buenos Aires: Hammurabi, 1982.

ZYLBERKAN, Mariana. Com os pais presos, Italo nunca conseguiu ter um lar. Agora On-Line. Disponível em: <http://www.agora.uol.com.br/ saopaulo/2016/06/1778238-com-os-pais-presos-italo-nunca-conseguiu-ter-umlar.shtml>. Acesso em: 30 jul. 2016. 